\title{
Investigation of copper/carbon nanocomposites modified with phosphorus-containing groups as inhibiting additives in mineral oil
}

\author{
I.N. Shabanova, ${ }^{1 *}$ S.M. Reshetnikov, ${ }^{1,2}$ V.I. Kodolov, ${ }^{3}$ \\ N.S. Terebova, ${ }^{1}$ R.V. Mustakimov ${ }^{3}$ F.F. Chausov ${ }^{1}$ \\ and S.G. Bystrov ${ }^{1}$
}

${ }^{1}$ Udmurt Federal Research Center, UB RAS, T. Baramzina str. 34, 426067 Izhevsk, Russian Federation

${ }^{2}$ Udmurt State University, Universitetskaya str. 1, 426034 Izhevsk, Russian Federation

${ }^{3}$ M.T. Kalashnikov State Technical University, Studencheskaya str. 7, 426069 Izhevsk, Russian Federation

*E-mail:xps@udman.ru

\begin{abstract}
The mechanism responsible for a protective anticorrosive preservative layer composed of mineral oil with various amounts of a phosphorus-containing copper/carbon nanocomposite was studied by the XPS method from room temperature to $700^{\circ} \mathrm{C}$. It was shown that a durable corrosion-protective layer was formed due to the donor-acceptor bonds between iron and phosphorous atoms. No changes in the nature of the contact between the protective layer and the steel substrate were found upon heating in a spectrometer chamber (in vacuo) with simultaneous acquisition of X-ray electron spectra. Optical microscopy surface analysis revealed that, at room temperature, the nanocomposites in mineral oil formed separate conglomerates on the steel surface. The conglomerates disintegrated into individual nanoparticles at temperatures of $100-200^{\circ} \mathrm{C}$, and nanoparticles distributed over the entire surface. The interactions between the nanocomposite and iron led to the formation of a durable protective coating that hindered the attack of corrosive surface environments. The corrosion protection of alloy-free steel was studied by a Monicor corrosion meter. A sulfate-chloride solution simulating moisture condensate during atmospheric corrosion was used as the corrosive medium. The study provided evidence that the incorporation of copper/carbon nanocomposites modified with phosphorus-containing groups could suppress atmospheric corrosion by $70-95 \%$.
\end{abstract}

Keywords: X-ray electron spectroscopy, optical microscopy, corrosion meter, anticorrosive layer, copper/carbon nanocomposite modified with phosphorus-containing groups.

Received: August 11, 2020. Published: October 27, 2020

doi: $\underline{10.17675 / 2305-6894-2020-9-4-11}$ 


\section{Introduction}

Mineral oils with various additives are known to be utilized for application of protective coatings on metals in order to prevent their corrosion damage [1]. The additives based on nitrated mineral oils are most effective [2-4]. A mineral-oil based lubricant containing nitrated mineral oil, synthetic fatty acid soaps, alkyl sulfates, alkyl sulfonates, and butyl ethers is described in [4]. The high anti-corrosion properties of the protective lubricant are attributed to a combination of complex additives of very diverse chemical nature. A drawback of the lubricant is its complex composition, which makes it challenging to prepare.

A series of studies [5-8] provided evidence of high protective properties shown by nanosized layers, which are formed by additives capable of chemosorption followed by chemical transformations, under conditions simulating atmospheric corrosion. In fact, under these conditions, complex nanocomposites largely suppressing corrosion are synthesized on the surface.

Nanocomposites are known to exhibit high reactivity due to the high surface energy of nanoparticles [9]. A phosphorus-containing copper/carbon nanocomposite is one such example of a highly active nanocomposite; its synthesis and properties were reported in [10]. An attempt was made to utilize this nanocomposite as a component of a mixed amine-based inhibitor to protect steel surface from corrosion in a neutral aqueous environment [11]. It should be noted that the increase in the protection efficiency was not as high as expected. Apparently, this is due to the fact that a steel surface in contact with an aqueous solution of neutral electrolyte contains iron oxides or hydroxides that prevent the formation of strong binding between the nanocomposite elements and the surface being protected.

We assumed that a protective coating containing a phosphorus-containing copper/carbon nanocomposite could be obtained in a hydrocarbon environment created by mineral oil applied to a steel surface. In this case, the contact between the steel surface and the aqueous solution of the inhibitor was excluded.

Based on this assumption, the purpose of this work was to study interatomic interactions and protective properties of a coating obtained with the use of the high chemical and adsorption activity of a copper/carbon nanocomposite modified with phosphorouscontaining groups that was added to the mineral oil base as an inhibitor.

For this purpose, a copper/carbon nanocomposite modified with phosphorouscontaining groups was prepared by the mechanochemical method [10].

\section{Experimental}

The copper/carbon nanocomposite modified with phosphorous-containing groups [10] and I-20 industrial oil [GOST 20799-88] were used.

The nanocomposite is a nanostructure including a copper cluster. The copper clusters with an average size of $15 \mathrm{~nm}$ are enclosed in carbon shells containing polyacetylene and carbyne fragments with unpaired electrons at their joints. According to the electron 
diffraction and X-ray photoelectron spectroscopy data, the phosphorus atoms are located between carbon fibers in $\mathrm{P}-\mathrm{C}$ bonds [12].

$\mathrm{X}$-ray photoelectron spectroscopic measurements were carried out on an X-ray electron magnetic spectrometer with a resolution of $10^{-4}$ and an instrument luminosity of $0.085 \%$ with excitation by the AlK $\alpha$ line at $1486.5 \mathrm{eV}$ [13]. The advantages of X-ray photoelectron magnetic spectrometers are due to separation of the magnetic electron analyzer from the vacuum chamber of the spectrometer. Hence, a sample can be heated in the chamber with simultaneous recording of XPS spectra.

An OLYMPUS SZ-STB2O optic microscope was used to obtain the optical images of the samples.

The pure I-20 industrial oil and I-20 industrial oil-based formulations containing 1, 5, 30 , 50, or $75 \mathrm{wt} . \%$ of the copper/carbon nanocomposite modified with phosphorouscontaining groups were tested as anti-corrosion preservative lubricants. The copper/carbon nanocomposite modified with phosphorous-containing groups was mixed with the base mineral oil and applied to a sample after grinding in a porcelain mortar.

Steel samples with $20 \times 20 \times 20 \mathrm{~mm}$ dimensions were cleaned with P-600 sandpaper, then covered with two layers of Zapon lacquer, leaving $400 \mathrm{~mm}^{2}$ as the working surface. Afterward, the samples were immersed in the test protective (preservative) lubricants for 5-7 min. Where, according to experimental procedure, the coated samples were heated in a muffle furnace, the non-working surfaces were insulted with Zapon lacquer after cooling the samples. The working surface exposed in a corrosion meter cell had an area of $400 \mathrm{~mm}^{2}$.

The protective properties of the formulations were examined by evaluating the corrosion rates of steel 08 samples. The corrosion rate was determined from the polarization resistance measured on a Monicor corrosimeter. Solution No. $7\left(\mathrm{NaCl} 30 \mathrm{mg} / \mathrm{L}, \mathrm{Na}_{2} \mathrm{SO}_{4}\right.$ $70 \mathrm{mg} / \mathrm{L}$ in accordance with GOST 9.502-82), which simulates a moisture condensate under weathering conditions of industrial cities, was employed as the corrosive medium. The corrosion rates were expressed in relative units as the fraction of the corrosion rate relative to an uncoated reference sample whose corrosion rate was taken as unity.

The samples were mounted on the corrosion meter sensor. After immersing the sensor with samples into the model corrosive medium, the corrosion rates were measured for two hours. Within this period of time, the corrosion rates of all samples reached constant values. These values were then used in the evaluation of the protective (inhibitory) effect. Measurements and data processing were carried out according to GOST 9.514-99.

\section{Results and Discussion}

We examined the chemical composition of the surface protective layers produced on steel upon adsorption of the preservation oil formulations containing 5 to $75 \%$ nanocomposite prepared in this way.

The X-ray photoelectron spectra of core levels such as C1s, O1s, Fe2p, P2p, Cu2p, and Cu3s were studied. 
The XPS study of the steel substrate surface onto which the protective coatings were subsequently applied showed that after cleaning from contamination by heating in the spectrometer chamber from 50 to $100^{\circ} \mathrm{C}$, oxides were removed from the steel surface and the Fe2p spectrum showed a $\mathrm{Fe}_{\text {pure }}$ peak (707 eV) (see Figure 1, spectrum 1).

In addition to the maximum in the range of pure iron, the Fe2p spectrum of the oil formulations applied on the steel substrate before heating showed two weak peaks attributed to $\mathrm{Fe}-\mathrm{O}$ surface oxides at $709-711 \mathrm{eV}$ (see Figure 1, spectrum 2). When the sample was heated from $\sim 50$ to $-100^{\circ} \mathrm{C}$ and up to $700^{\circ} \mathrm{C}$, the position of the main peak at $707 \mathrm{eV}$ in the $\mathrm{Fe} 2 \mathrm{p}$ spectrum corresponded to pure iron or the $\mathrm{Fe}-\mathrm{P}$ covalent (donor-acceptor) bond (see Figure 1, spectrum 3).

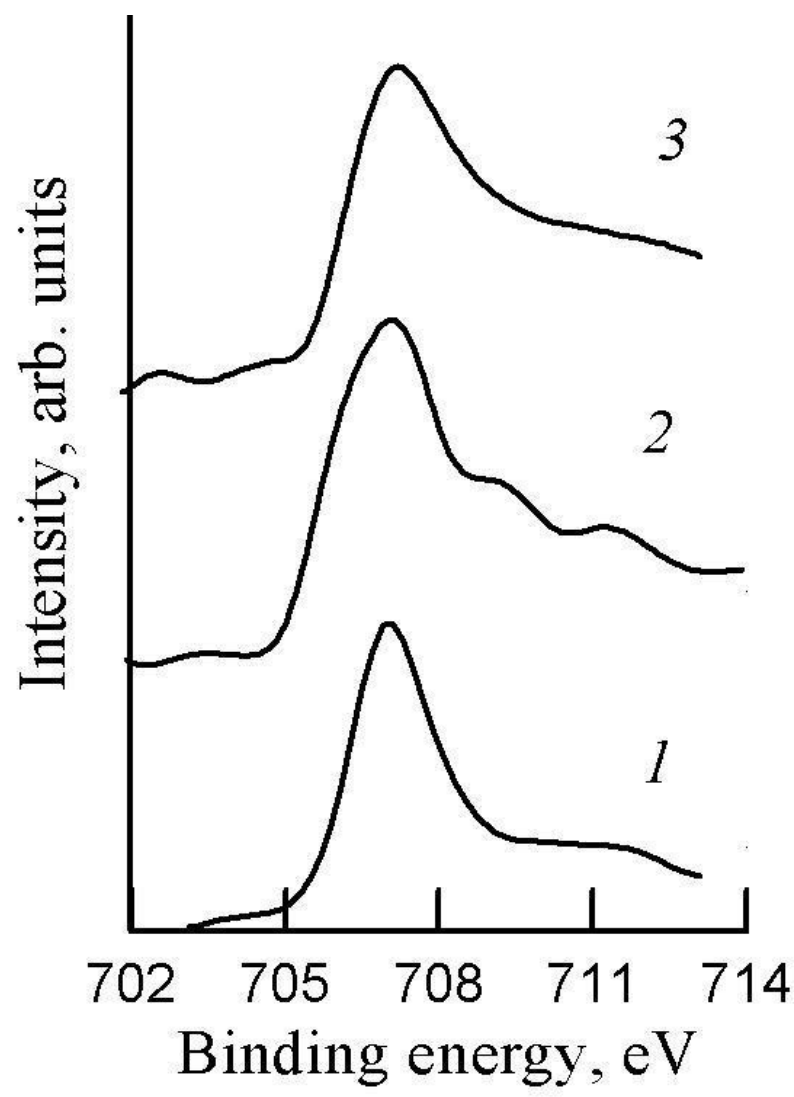

Figure 1. Fe2p spectra of uncoated steel surface upon heating (1), steel surface with the protective coating without heating (2), and steel surface with the protective coating upon heating (3).

In addition to the main $\mathrm{P}-\mathrm{Fe}$ peak at $130 \mathrm{eV}$ in the $\mathrm{P} 2 \mathrm{p}$ spectrum of the non-heated sample, a weak maximum at high bond energies corresponding to the $\mathrm{P}-\mathrm{O}$ bond was recorded (Figure 2, spectrum 1) that corresponded to the fragments adsorbed on the surface. When the sample was heated to $50-70^{\circ} \mathrm{C}$, this maximum disappeared. However, an intense $\mathrm{P}-\mathrm{Fe}$ maximum with a bond energy of $130 \mathrm{eV}$ persisted (Figure 2, spectrum 2). The $\mathrm{P}-\mathrm{Fe}$ bond persisted even when the sample was heated to $700^{\circ} \mathrm{C}$ or higher in vacuo. 


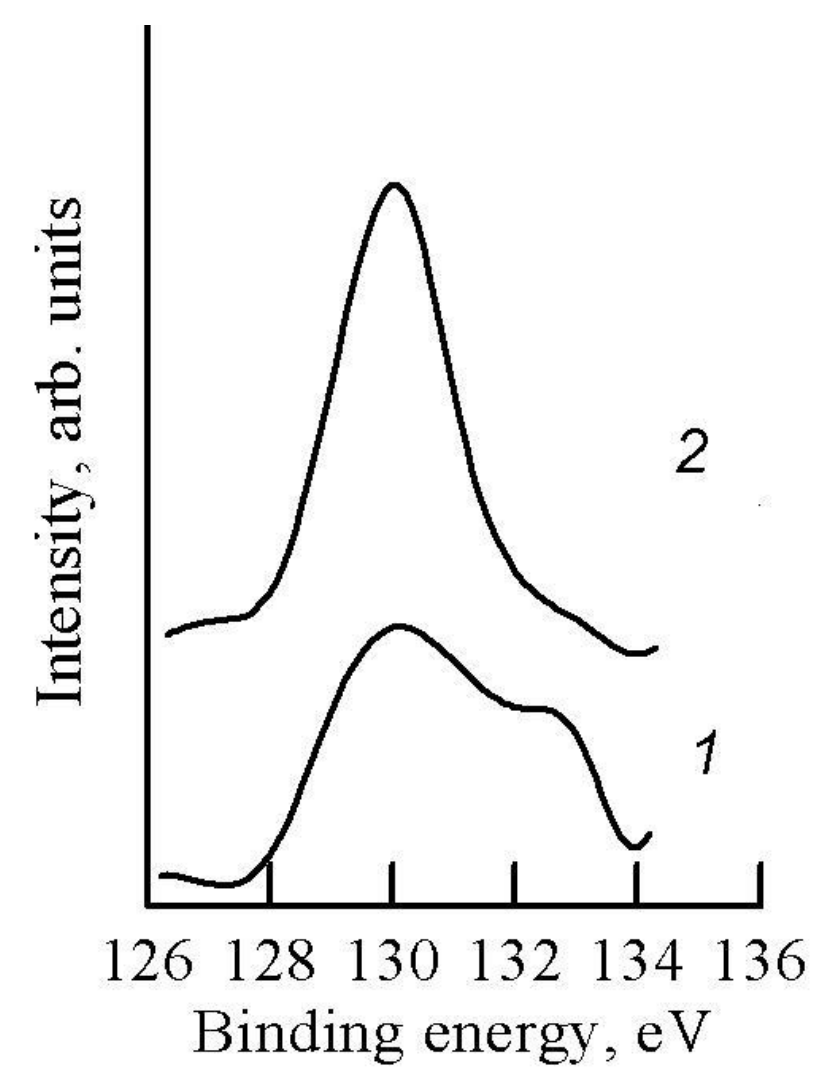

Figure 2. P2p spectra of the steel surfaces with a protective coating before (1) and after heating (2).

No copper was found in the surface layers of the protective coating.

The peak position in the $\mathrm{C} 1 \mathrm{~s}$ spectrum $(285 \mathrm{eV})$ corresponded to the $\mathrm{C}-\mathrm{H}$ bond in the hydrocarbons, but after the sample was heated, the contrast ratio of the spectrum decreased by half. No formation of $\mathrm{Fe}-\mathrm{C}$ bonds was found.

Thus, the phosphorus atoms are bonded to carbon ( $\mathrm{C}-\mathrm{P}$ bond) in the copper/carbon nanocomposite; the $\mathrm{P}-\mathrm{O}$ bond that is quite strong under ordinary conditions is not formed even at room temperature. The reason lies in the high reductive activity of the copper/carbon nanocomposite modified with phosphorous-containing groups, including the highly active carbyne and polyacetylene moieties, combined with the redox catalytic activity of copper/carbon moieties in which copper as the transition metal with a highly labile $3 \mathrm{~d}$ subshell serves as a common redox catalyst, and a developed carbon matrix acts as an electron density transfer carrier. The $\mathrm{C}-\mathrm{P}$ bond is broken on contact of the copper/carbon nanocomposite modified with phosphorous-containing groups with steel surface, and the phosphorus atoms form a strong covalent (donor-acceptor) bond with iron. Therefore, the copper/carbon nanocomposite modified with phosphorous-containing groups is involved in the creation of a highly efficient anticorrosive protective coating both as a depot of reactive phosphorus atoms enclosed in the carbon matrix and as a transport structure that ensures the delivery of reactive forms of phosphorus to the steel surface to form an iron phosphide layer. 
It is crucial that due to the structure of the copper/carbon nanocomposite modified with phosphorous-containing groups determined by the technology of its preparation, copper nanoparticles are encapsulated in the carbon matrix, which prevents their direct contact with the steel surface. This eliminates the stimulating effect of nanoparticles of metal copper on the corrosion of the steel surface.

An OLYMPUS SZ-STB2 optical microscope was used to obtain the surface images of the samples at room temperature and after heating to $50-100^{\circ} \mathrm{C}$. This study revealed that at room temperature, the nanocomposites in the mineral oil formed separate conglomerates on the steel surface (Figure 3). When the samples were heated to $50-100^{\circ} \mathrm{C}$, these conglomerates disintegrated and the nanocomposite was evenly distributed in the mineral oil over the entire coating surface (Figure 4).

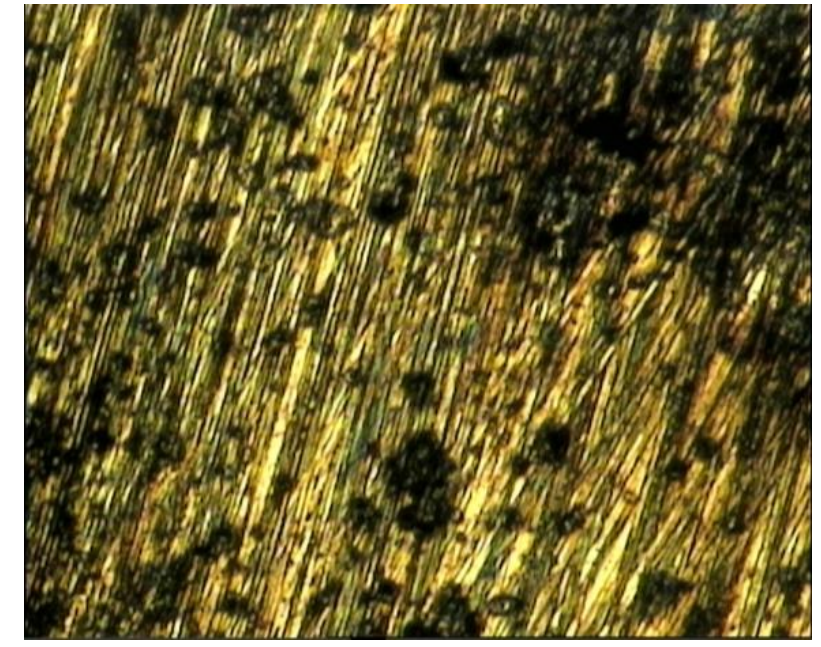

Figure 3. Optical images of the protective coating at room temperature. The eyepiece readings were 3.5 , and the frame size was $740 \times 580 \mu \mathrm{m}$.

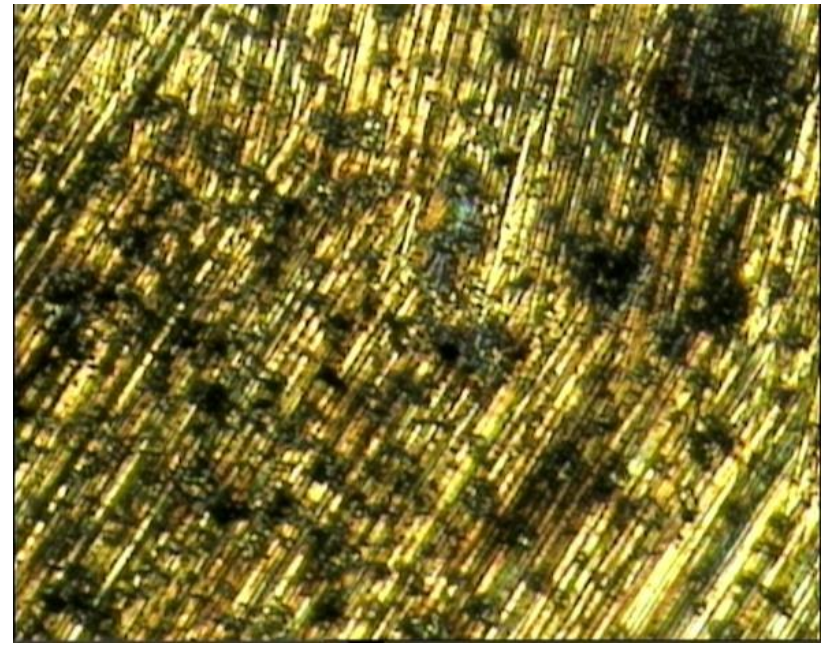

Figure 4. Optical images of the protective coating after heating up to $50-100^{\circ} \mathrm{C}$. The eyepiece readings were 3.5 , and the frame size was $740 \times 580 \mu \mathrm{m}$.

The protective properties of the formulations were examined using the Monicor corrosion meter. The Monicor corrosion meter enabled the measurement of relative corrosion rates. The corrosion rate in the background solution was taken as 1 .

The samples for testing were prepared by dipping into a suspension of the nanocomposite in I-20 industrial oil. After that, some samples were subjected to thermochemical treatment, i.e., heated for $20 \mathrm{~min}$ in a muffle furnace at 100 and $200^{\circ} \mathrm{C}$ in air. After cooling, the corrosion rates of the samples were measured by the Monicor corrosion meter. Table 1 summarizes the test results. 
Table 1. The corrosion rates in the model corrosion medium, arb. units.

\begin{tabular}{cccc}
\hline $\begin{array}{c}\text { Composition of the } \\
\text { protective coating (wt. \% } \\
\text { nanocomposite in I-20 } \\
\text { mineral oil) }\end{array}$ & \multicolumn{2}{c}{ The corrosion rate, arb. units, at activation temperature, ${ }^{\circ} \mathbf{C}$} \\
\hline Reference (uncoated steel) & 1 & $\mathbf{1 0 0}$ & $\mathbf{2 0 0}$ \\
0 & 0.91 & 0.90 & 0.90 \\
1 & 0.88 & 0.88 & 0.85 \\
5 & 0.88 & 0.72 & 0.70 \\
30 & 0.72 & 0.70 & 0.65 \\
50 & 0.68 & 0.12 & 0.10 \\
75 & 0.66 & 0.08 & 0.06 \\
\hline
\end{tabular}

Note. Legend: Reference (without a coating); 0 - I-20 oil without the NC additive; numbers 1, 5, 30, 50, and 75 correspond to the NC concentration (wt. \%) in I-20 oil.

It was found in the experiments that heating of a sample coated with a mixture of the oil with the nanocomposites studied to $100-200^{\circ} \mathrm{C}$ increased its chemical activity. As a result, a protective coating was formed on the surface that reduced the corrosion rate by 70-95\% depending on the nanocomposite concentration.

Thus, a formulation with a high nanocomposite content becomes efficient in forming a durable surface layer only after thermal activation.

\section{Conclusion}

The protective coating produced by thermal treatment of a suspension of a copper/carbon nanocomposite modified with phosphorous-containing groups in a hydrocarbon medium consisting of a mineral (petroleum) oil applied to a steel surface was studied.

The X-ray photoelectron spectra of the adsorbed layers on the steel surface were recorded. The interatomic interactions in these layers were studied.

It was shown that the formation of a protective layer upon adsorption of the inhibited mineral-oil formulation occurs due to the formation of covalent (donor-acceptor) bonds between iron and phosphorus atoms of the nanocomposite.

Corrosion tests revealed that the thermal activation of protective surface layers on steel surface from preservative oil formulations comprising 5 to $75 \%$ copper/carbon nanocomposite modified with phosphorous-containing groups increased the chemical activity of the nanocomposite. The resultant efficient protective layer on steel surface reduces the corrosion rate by $70-95 \%$ depending on the nanocomposite concentration. 


\section{Acknowledgements}

Thus study was carried out within the framework of a State task (state registration no. AAAA17-117022250040-0). The investigations were performed using the facilities of the Center for collective usage "Center of physical and physicochemical methods of analysis, study of properties and characteristics of surfaces, nanostructures, materials, and products" of UdmFTIS UB RAS supported by the Ministry of Science and Higher Education of the Russian Federation under the Federal Target Program "Study and Development in Priority Areas of Development of the Scientific and Technological Complex of Russia for 20142020" (unique project identifier: RFMEFI62119X0035).

\section{References}

1. T.I. Bogdanova and Yu.N. Shekhter, Inhibited oil compositions for corrosion protection, 1984, Moscow, Khimiya, 284 (in Russian).

2. Yu.N. Shekhter, N.E. Legezin, S.A. Murav'eva and N.O. Muryzyova, Corrosiological principles of the protection of inner metallic surfaces with inhibitors and inhibited formulations, Prot. Met., 1998, 33, no. 3, 239-246 (in Russian).

3. Yu.N. Shekhter, S.A. Murav'eva, N.L. Puzevich, V.M. Podchinov and S.A. Egorov, The use of the corrosion inhibitor AKOR-1B for improving the protective properties of lubricants, Prot. Met., 1998, 34, no. 3, 322-324 (in Russian).

4. Yu.N. Shekhter, T.I. Bogdanova, V.M. Bakaleynikov, M.A. Zubareva, E.V. Shkaruba, A.E. Aliev and A.V. Ustalov, Protective lubricant, RF Patent 2017798 C1, 15.08.1994 (in Russian).

5. Ya.G. Avdeev, D.S. Kuznetsov, M.V. Tyurina and M.A. Chekulaev, Protection of nickel-chromium steel in sulfuric acid solution by a substituted triazole, Int. J. Corros. Scale Inhib., 2015, 4, no. 2, 146-161. doi: 10.17675/2305-6894-2015-4-1-146-161

6. N.A. Gladkikh, M.A. Maleeva, L.B. Maksaeva, M.A. Petrunin, A.A. Rybkina, T.A. Yurasova, A.I. Marshakov and R.Kh. Zalavutdinov, Localized dissolution of carbon steel used for pipelines under constant cathodic polarization conditions. Initial stages of defect formation, Int. J. Corros. Scale Inhib., 2018, 7, no. 4, 683-696. doi: 10.17675/2305-6894-2018-7-4-14

7. O.Yu. Grafov, L.P. Kazansky, S.V. Dubinskaya and Yu.I. Kuznetsov, Adsorption of depocolin and inhibition of copper dissolution in aqueous solutions, Int. J. Corros. Scale Inhib., 2019, 8, no. 3, 549-559. doi: 10.17675/2305-6894-2019-8-3-6

8. I.N. Shabanova, S.M. Reshetnikov, E.A. Naimushina and N.S. Terebova. XPS investigation of adsorption protective layers based on industrial inhibited oil, Int. J. Corros. Scale Inhib, 2020, 9, no. 2, 903-911. doi: 10.17675/2305-6894-2020-9-3-6

9. I.P. Suzdalev, Nanotechnologies: physicochemistry of nanoclusters and nanomaterials, 2009, Moscow, Librokom, 592 (in Russian) 
10. R.V. Mustakimov, Method for modification of metal/carbon nanostructures with ammonium polyphosphate, RF Patent No. 2694092 C1, 09.07.2019, Bul. No. 19 (in Russian).

11. M.A. Pletnev，O.A. Ovechkina， N.C. Buldakova， N.V. Novikova and V.K. Miller, Effect of metal-carbon nanocomposites on protective effect of corrosion inhibitors, Intell. Syst. Prod., 2014, no. 1, 150-152 (in Russian).

12. V.I. Kolodov, V.V. Trineeva, N.S. Terebova, I.N. Shabanova, T.M. Makhneva, R.V. Mustakimov and A.A. Kopylova. The changes in the electron structure and magnetic characteristics of modified copper/carbon nanocomposites, Chem. Phys. Mesoscopy, 2018, 20, no. 1, 72-79 (in Russian).

13. I.N. Shabanova, V.A. Trapeznikov, L.V. Dobysheva, D.V. Varganov, V.G. Karpov, L.G. Kovner, O.I. Klyushnikov， Y.G. Manakov， E.A. Makhonin, A.V. Khaidarov, Advanced automated x-ray photoelectron magnetic spectrometers: spectrometer with technological attachments and manipulators, melt spectrometer, Izv. AN SSSR, 1986, 50, no. 9, 1677-1682 (in Russian). 